\title{
Aproximación al diseño \\ surgido a partir de la posmodernidad \\ bajo la perspectiva de la estética daliniana
}

Sandra Medina Bueno ${ }^{1}$

Universidad de Málaga. España

RECIBIDO: 23.12.2015 / ACEPTADO: 15.12.2016

\begin{abstract}
Resumen
El surrealismo desafío las normas del arte a través de las representaciones de los sueños, deseos, paradojas y dualidades. En ese límite que caracteriza a Dalí, entre la cordura y la locura, se encuentra la marca personal del artista, creadora de un nuevo arte y un nuevo estilo de vida, influenciando con sus ideales a gran parte del diseño que va a surgir a partir de entonces. Este breve estudio pretende demostrar la influencia de su estética en algunos de los diseños surgidos a partir de la posmodernidad y hasta nuestros días.
\end{abstract}

Palabras clave: Dalí, surrealismo, posmodernidad, diseño industrial.

Approach to design emerged from Postmodernity under the perspective of Dali's aesthetics

Abstract

Surrealism challenged the rules of the art through the representations of the dreams, desires, paradoxes and dualities. This limit that characterizes Dali between sanity and insanity is, perhaps, the personal mark of the artist, creator of a new art and a new style of life, influencing with his ideals to much of the design that will arise from then. This brief study aims to show the influence of his aesthetics in some of the designs from postmodernism to the last days.

Keywords: Dali, surrealism, postmodernism, industrial design.

Hasta principios del siglo pasado los objetos dormían una plácida siesta sin sobresaltos. Su despertar se efectuó en dos tiempos. El primero fue el del cubismo [...]. El segundo tiempo lo marcaron los surrealistas. Los objetos sólo dormían y había que despertarlos, sacudirlos?

M. Rodríguez-River

\footnotetext{
1 Graduada en Historia del Arte por la Universidad de Málaga. Máster en Desarrollos Sociales de la Cultura Artística por la Universidad de Málaga. Beca de Colaboración en el Departamento de Historia del Arte de la UMA. Actualmente cursando doctorado en Estudios Avanzados en Humanidades. Correo-e: sandra_medina93@hotmail.com

${ }^{2}$ RODRÍGUEZ RIVERO, M. “El objeto, despierto” http://www.revistadelibros.com/articulos/el-objeto-despierto 20.05.2015.
} 


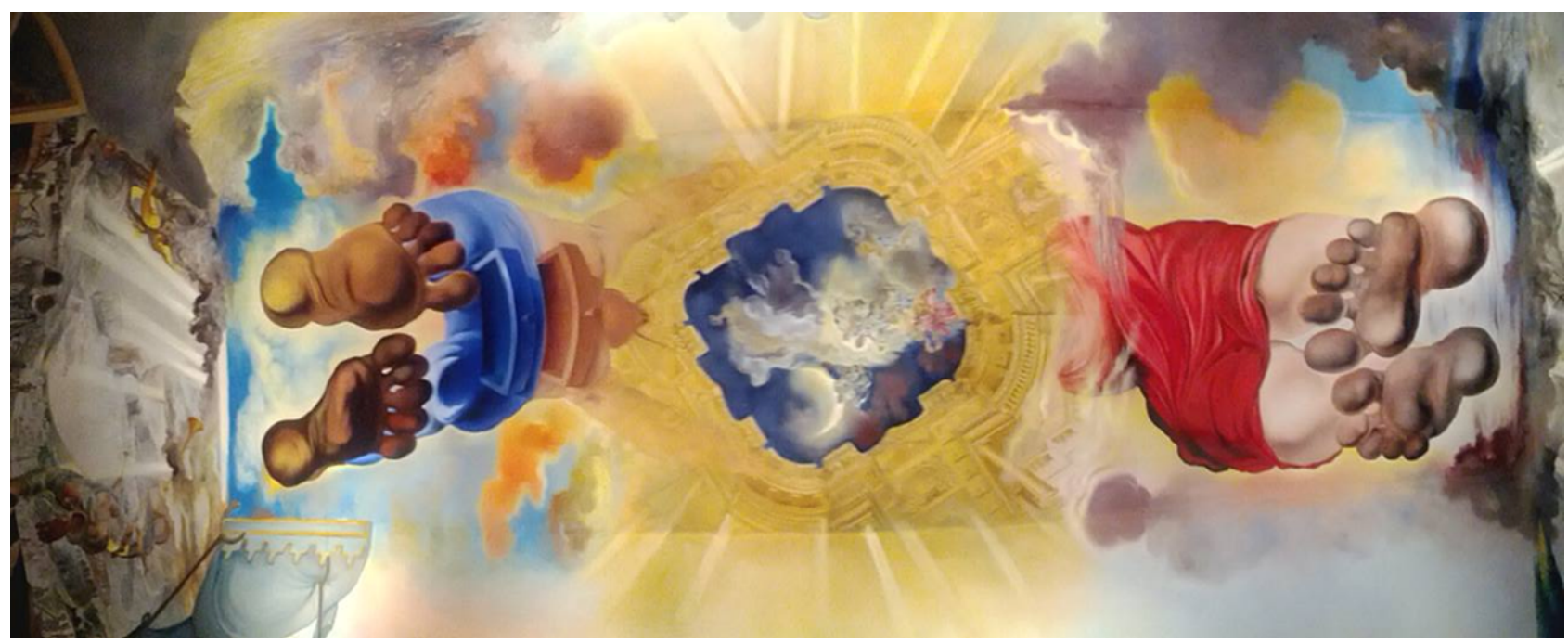

Fig. 1. Techo de una de las salas del Teatro-Museo Dalí, Figueras.

\section{El surrealismo: contexto y características más significativas}

El siglo XX trae consigo una nueva realidad: dadaísmo, surrealismo futurismo, modernismo y constructivismo comparten un interés por el objeto y la identidad del mismo. Todos estos cambios hacen que nos situemos ante una nueva forma de sensibilidad durante la posmodernidad.

Por otro lado, el papel que protagonizó Dalí, dentro del movimiento surrealista, fue fundamental para influenciar al diseño que tuvo lugar a finales del siglo $X X$ y principios del $X X I$. $Y$ es que, a partir del siglo $X X$, se produce esta multiplicidad de significados vinculados con una nueva objetividad ante el mundo y los objetos que se presentan ante nosotros.

Dalí ha dotado al surrealismo de un instrumento de primer orden en su especie, el método paranoico-crítico, que se mostró ya desde el principio capaz de aplicar indistintamente a la pintura, a la poesía, al cine, a la construcción de objetos surrealistas típicos, a la moda, a la escultura, a la historia del arte, e incluso, llegado el caso, a cualquier tipo de exégesis. ${ }^{3}$

Para llegar a la conciencia integral de sí mismo, el hombre debe descifrar ese mundo de deseos que residen en el inconsciente y el surrealismo, a través de los sueños, intentará resolver esas cuestiones vitales, ya que: "Soñar es un medio de conocimiento, tanto como pensar, y hay que analizarlo bajo este concepto" 4 .

Le conceden primacía a la imaginación frente a la razón (la cual se pretende eliminar), para llegar a ese escalón superior que sería esa surrealidad, esto es, algo superior a la propia realidad5. Se produce, entonces, un momento en el que el artista se encuentra entre el sueño y la realidad en el que, a veces, es complicado distinguir entre ambas.

\footnotetext{
${ }^{3}$ IBARZ,V.IVILLEGAS, M. "El método paranoico-crítico de Salvador Dalí", Revista de Historia de la Psicología, vol. 28, núm. 2/3, 2007, 107-112, p.109.

${ }^{4}$ Ibidem, p. 34.

${ }^{5}$ BARREIRO LEÓN, B. “La estética surrealista”, Eikasia Revista de Filosofía, núm. 58, 2014, p. 448.
} 
Esa locura va a estar muy influenciada por el automatismo psíquico, método que no entiende de raciocinio, reglas o criterios objetivos, sino todo lo contrario, lo subjetivo como componente válido, lo que da lugar a una pluralidad de significados $^{6}$. El paranoico utiliza las visiones de su imaginación con la finalidad de "interpretar los objetos del mundo exterior y otorgarles un sentido diferente del habitual" 7 . El surrealismo consigue, por tanto, establecer un rol importante a la imaginación, la cual va a formar parte importantísima en los objetos diseñados por Dalí.

Puelles Romero ${ }^{8}$ dota al objeto surrealista de varias características: 'inesperado', 'ininteligible', 'inidentificables' e 'inexplicables'. Todo ello amplía las posibilidades de lo real:

[...] los objetos surrealistas, los cuales pasan por ser cosas entre las cosas, ni son sólo cosas ni son simples obras artísticas: ni sirven como lo hacen los útiles ni son imágenes o representaciones de índole artística y, no obstante, hasta podrían obtener alguna excéntrica utilidad (podrían incluso servir para ser expuestas en los museos y, cómo dudarlo, son imágenes y acaso más que imágenes).

\section{A. Bretón}

Por tanto, a partir de los 90, la dimensión que abarcaba el diseño se va a ampliar, desarrollando fuerzas enfocadas a "lo más profundo del hombre", con resultados que busquen "satisfacer deseos ocultos, ofrecer sueños, en un mundo que no tiene tiempo para soñar"9.

\section{Anti-diseño y surrealismo: estética vs ética}

El diseño del objeto, como operación creativa, tiene esas cualidades de unicidad y distinción, típicas de la obra de arte, que lo distinguen de cualquier otro diseño y constituyen su auténtica identidad.

G. Albera N. Monti ${ }^{10}$

Tras la Segunda Guerra Mundial, Italia se situó en una posición primordial dentro del ámbito del diseño internacional, con artistas como Albini, Carlo Mollino, Gìo Ponti Poco después surgieron diferentes grupos, entre ellos Archizoom Associati, Superestudio (ambos fundados en Florencia en 1966), Alchimia (Milán, 1976) y Memphis (Milán, 1981) ${ }^{11}$.

La mayoría de ellos realizaban objetos únicos y novedosos, evitando, así, la producción en serie, basándose en la utilización de las líneas curvas, retorcidas y la no presencia del ángulo recto. Todos ellos buscaban separarse de las reglas del funcionalismo mediante resultados muy innovadores.

\footnotetext{
${ }^{6}$ BARREIRO LEÓN, B. op. cit. p.458.

${ }^{7}$ DUPLESSIS, Y. op. cit. p.38.

8 PUELLES ROMERO, L. El desorden necesario: filosofía del objeto surrealista. Málaga: Universidad de Málaga, Servicio de Publicaciones, Málaga 2002, p. 25.

${ }^{9}$ BÖRNSEN-HOLTMANN, N. Italian Design, Taschen, 1995, pp.146-148.

${ }^{10}$ ALBERA, G./MONTI, N. El diseño italiano, Gustavo Gili, Barcelona 1989, p. 10.

11 Ibidem, p. 6.
} 


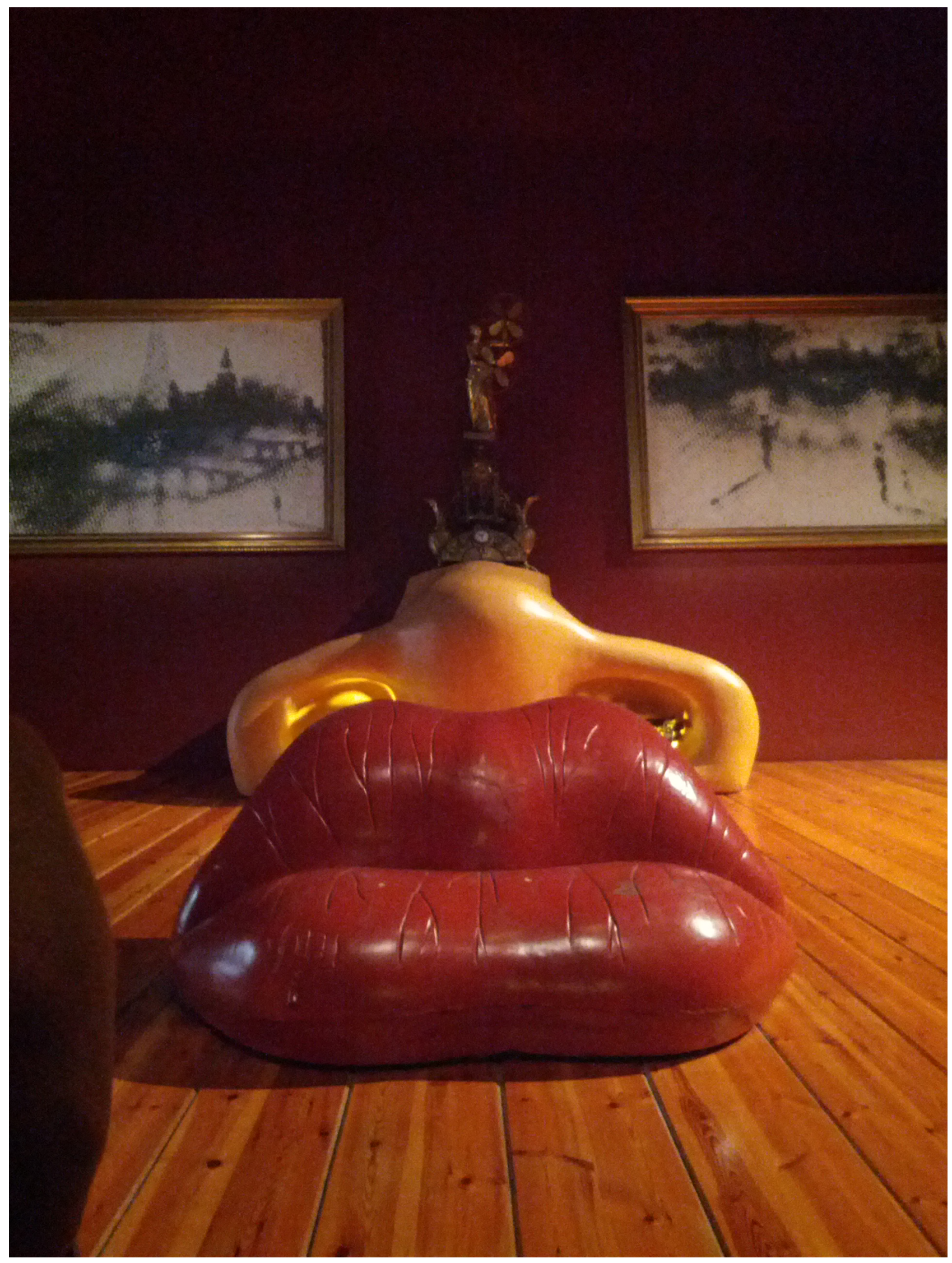

Fig. 2. Sala Mae West, Salvador Dalí, Museo Dalí, Figueras. 
Con estos grupos surge este nuovo design, es decir, "el mueble se convierte en palabra, oración, cita literaria o poética [...] reconciliando el arte y la poesía con la industria"12.

Por tanto, un elemento importante que entra en juego a partir de ahora es la experiencia estética en el ámbito de la creación de objetos, independientemente del sentimiento que genere en el espectador: rechazo, admiración, asombro... Este tipo de piezas llevan un valor estético más impactante para el espectador del que pudiera hacernos experimentar un objeto enfocado a lo práctico y funcional. Gozar de esa experiencia tan particular es lo que lo acerca a este movimiento. La principal aportación del anti-diseño italiano es que ampliaba esa finalidad meramente funcional que hasta entonces había tenido el diseño, algo que va a tener en común con el diseño surrealista.

Al igual que sucede con Dalí, la elección de las formas del diseño no hacen que el resultado sea un objeto más confortable. Sin embargo, ¿por qué se escoge esta tipología? Como hemos dicho antes, nos alejamos de los ideales de funcionalidad, racionalidad y practicidad propios del diseño anterior.

En 1970, realizado por Lomazzi, De Pas y D’Urbino, el Sillón Joe, cuya forma, representando un guante de béisbol, parece guardar connotaciones de esa surrealidad al escoger partes del cuerpo y objetualizarlas a modo de mobiliario, algo que nos podría recordar al Sillón Bocca.

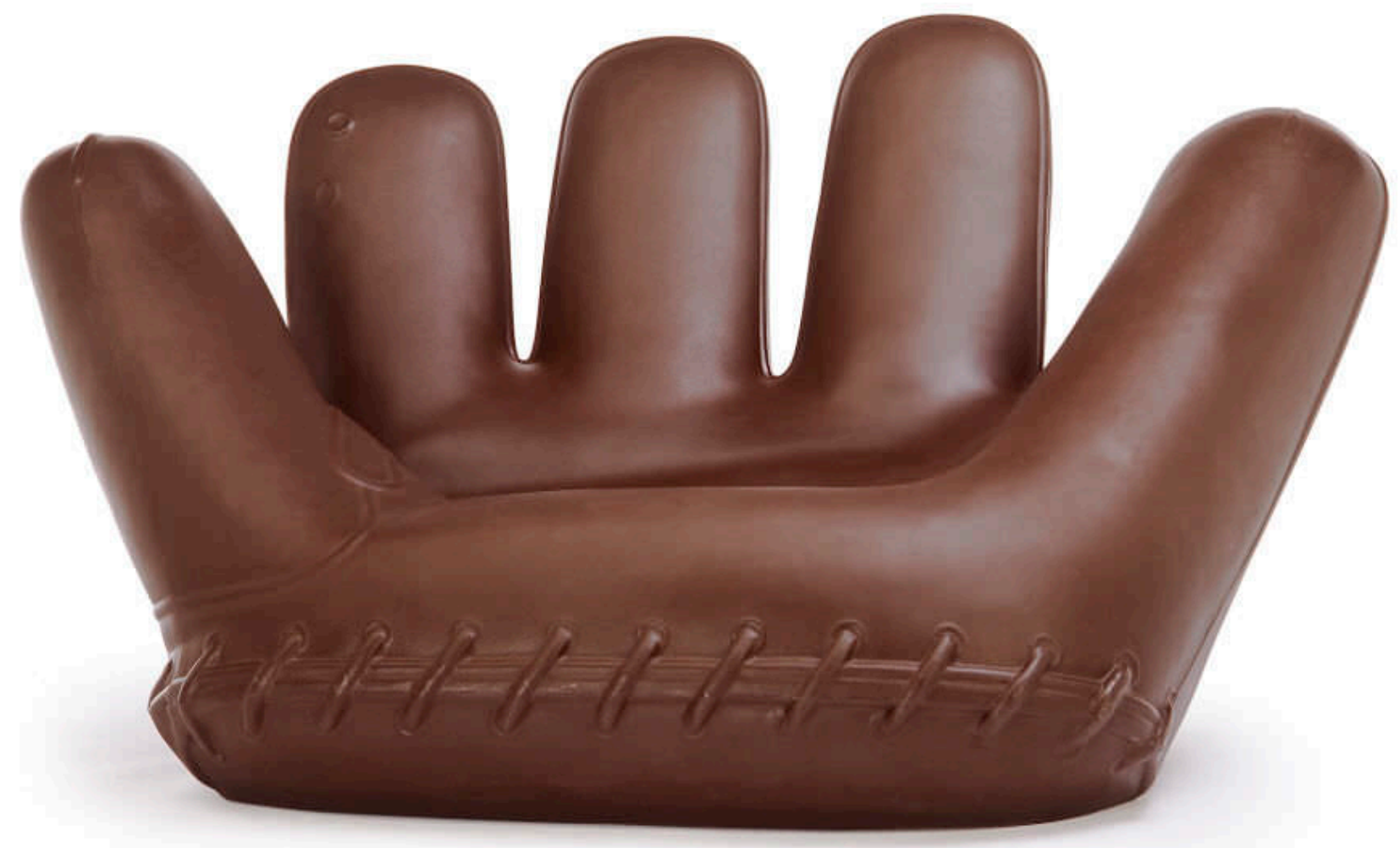

Fig. 3. Sillón Joe, por Lomazzi, De Pas y D’Urbino, 1970.

\footnotetext{
${ }^{12}$ FITOUSSI, B. Memphis, H. Kliczkowski, Madrid 1998, p. 13.
} 
¿No parece haber una burla hacia todo lo anterior, al modo en que el Dadaísmo y el Surrealismo rechazaban los movimientos anteriores? ¿No hay un afán de renovación, de crear algo nuevo y diferente a la normativa previa establecida? ¿No es esto lo que se ha denominado como 'anti-diseño? Y, sin embargo, es diseño y, guarda a la vez, connotaciones artísticas pues, muchos de estos grupos van a ampliar la dimensión del diseño industrial y, con ello, las posibilidades de creatividad. Además, gracias a ellos, la posmodernidad va a reforzar la división entre el diseño y la industria para lograr un mayor acercamiento al arte, anteponiendo la configuración estilística del objeto a su funcionalidad.

El surrealismo ha sido sin duda, el 'ismo' que más ha permeado la civilización contemporánea [...]. Su 'reencuentro' con los objetos ha sido esencial en la configuración de importantes aspectos nuestra vida cotidiana: la moda, el diseño de nuestros enseres, las técnicas de captación publicitaria. Los surrealistas, apoyados en las técnicas de desvelamiento del inconsciente, interrumpieron durante un instante el sueño de los objetos, apelando a su 'belleza convulsa', latente y - según creyeron - espiritualmente liberadora.

M. Rodríguez Rivero ${ }^{13}$

\section{El 'despertar' surrealista a partir de diseños de la posmodernidad}

Muchas de estas características que se proponían en el siglo anterior se muestran hoy en día en estos objetos.

En primer lugar, podemos citar algunos de los diseños de Judson Beaumont, de quien destacaríamos su Little Black Dresser, cuya forma, basada en la silueta de una mujer dividida en cajones, nos pueden recordar a la Venus de Milo con cajones de Dalí (1936), a su cuadro Jirafa en llamas (1937), o incluso, a lo que años más tarde, dentro del contexto de la posmodernidad, realizaría el japonés Shiro Kuramata con su Drawers in a irregular form (1970), obra que le otorgó un gran prestigio internacional. Vemos, pues, cómo el uso de los cajones es una constante en la obra surrealista y daliniana, relacionados con el subconsciente y el psicoanálisis de Freud, para quien éste resultaba ser el único capaz de abrir esos cajones del cuerpo humano ${ }^{14}$. Este artista parece haber hecho algo similar al apropiarse de esta iconografía, trasponiéndola a un objeto cotidiano.

Cuando el diseño adopta las maneras del arte para dar a conocer su quehacer, ¿se mantienen las diferencias entre ambas disciplinas perfectamente delimitadas o, por el contrario, se contagian entre sí y empiezan a compartir algo más que los medios de difusión?

A.Calvera ${ }^{15}$

Por otro lado, el diseñador Valentin Loellmann busca, mediante sus diseños, imitar los elefantes dalinianos emulando esas patas tan alargadas y delgadas en los muebles que realiza, cuyos diseños

\footnotetext{
${ }^{13}$ RODRÍGUEZ RIVERO, M. El objeto, despierto http://www.revistadelibros.com/articulos/el-objeto-despierto 20.05.2015

14 PANERO GÓMEZ, A. “Dalî's Gradiva”, Revista de Investigación Arte y Ciudad, núm. 1, 2012, p. 22.

${ }^{15}$ CALVERA, A. y otros, Arte ¿? Diseño, Gustavo Gili, 2003, p. 12.
} 
resultan muy curiosos, inestables e irracionales a la vez. La gran similitud que aquí podemos encontrar son los elefantes de Dalí que aparecen en obras como La tentación de San Antonio. Ambas figuras muestran esa aparente fragilidad en las partes inferiores, mediante esas patas tan finas y endebles que parecen que vayan a derribarse, de un momento a otro, en contraposición con la solidez del cuerpo superior. Todo ello, con un predominio de la verticalidad y dándonos esa impresión de inestabilidad, de nuevo, con esa sensación de no pertenecer a un mundo racional, sino a otra dimensión onírica completamente ajena a la nuestra, en donde, en el caso del mobiliario parece que de un momento a otro va a despertar y cobrar vida.
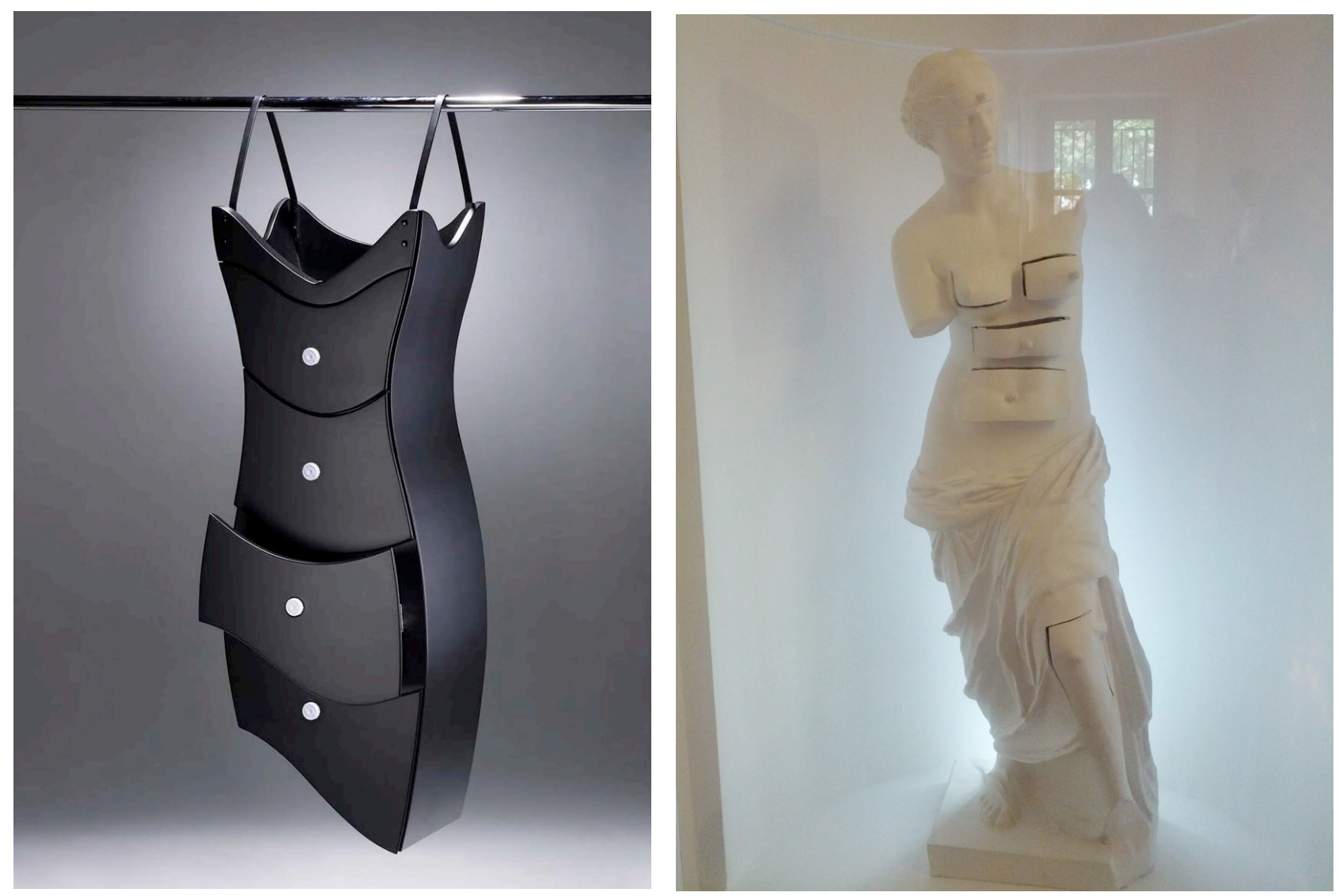

Fig. 4. (Izq.) Little Black Dresser, Judson Beaumont.

Fig. 5. (Der.) Venus de Milo, Salvador Dalí, 1936, Museo-Teatro Salvador Dalí, Figueras.

Entre el diseño y la escultura se encuentra el diseñador Michael Beitz, quien dota de una composición antifuncional a sus obras. Algunas de ellas son Cloud Chair, un sillón cuya forma puede contener alusiones a elementos sexuales, o su It's no picnic table, la cual parece derretirse sobre la reja que la sujeta, a modo de formas blandas. Su diseño, aunque a veces reiterativo, no deja de ser original y rompedor.

Otro caso es el del artista David Pompa, quien realiza una combinación de arte minimal y surrealista, ya que esas patas con forma humana pueden recordarnos a las de la Silla Leda de Dalí. En el otro ejemplo, perteneciente a la misma colección, utiliza el módulo inferior a modo de silla de ruedas y la parte superior que nos podría recordar a la forma de un ataúd acolchado. En relación a estos diseños el artista dirá: 
I see this objects as a starting point to get away of the stereotypical situation between office chairs, tables and humans.

D. Pompa ${ }^{16}$
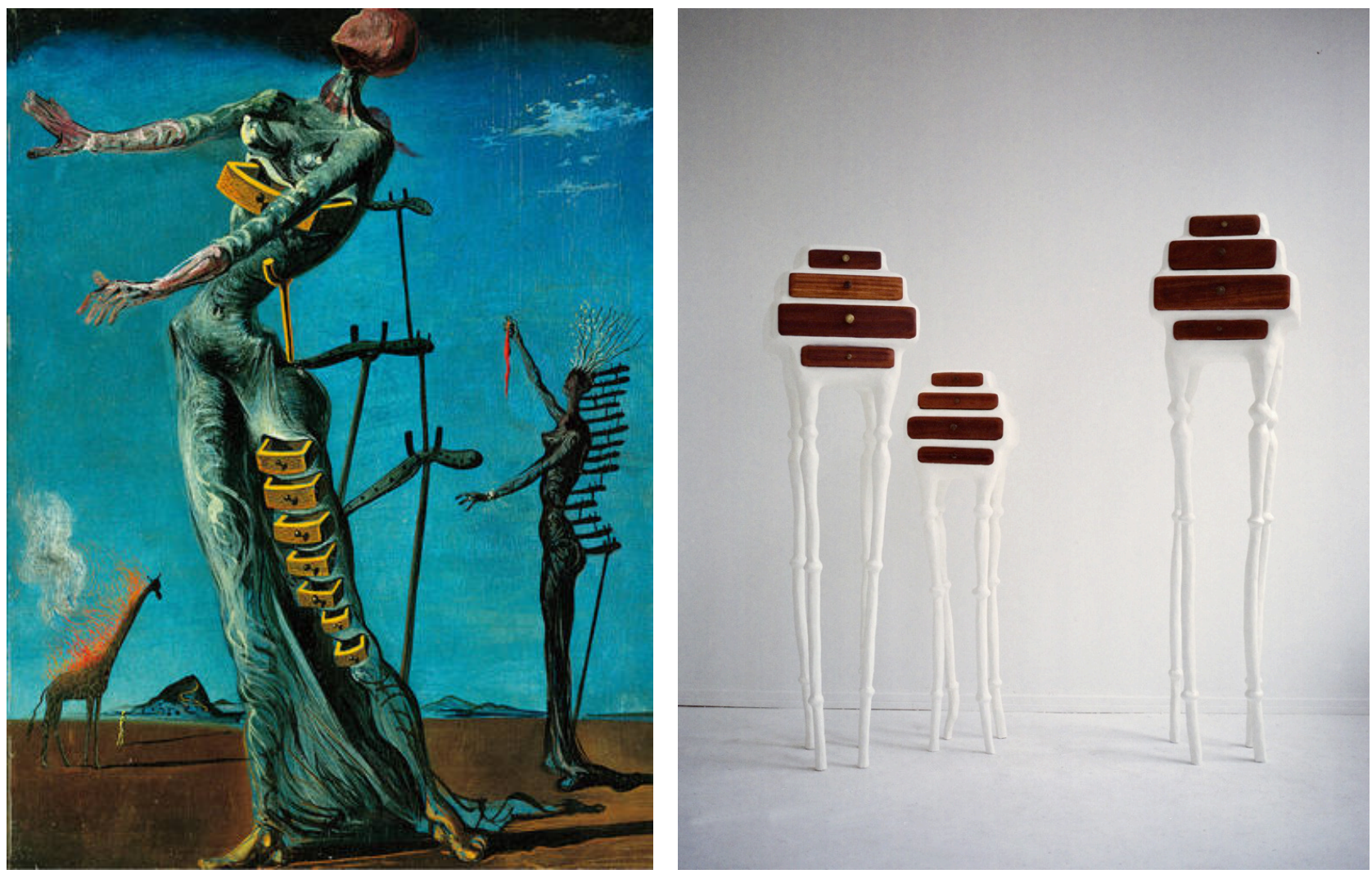

Fig. 6. (Izq.) Jirafa en Ilamas, Salvador Dalí, 1936-37, Fundación Gala-Salvador Dalí.

Fig. 7. (Der.) Serie de muebles de estética surrealista, Valentin Loellman.

Otro ejemplo más podría ser la Cuchara de amor que realiza Nedda El-Asmar, en relación con la obra de Dalí, Retrato de Picasso (1947), la cual parece haber sido traspuesta directamente al ámbito de la vida real con esa forma tan alargada y curva que guarda tanta similitud con la de la obra pictórica. La originalidad de estas propuestas podemos verla en la aportación de un lenguaje hasta entonces desconocido o, el hecho de haberse desplazado de las reglas más convencionales y asentadas ${ }^{17}$. Parece como si la artista hubiera extraído del lienzo el objeto y lo hubiera presentado en la vida real, con esa estructura tan alargada y curva. Seguramente estemos ante uno de los movimientos que más han influido en este diseño 'anti-funcional', debido a ese afán por hacer cosas imposibles.

El surrealismo buscaba, como movimiento de vanguardia (al igual que el dadaísmo) "romper con el concepto tradicional del arte [...] y, por otra [(parte)], proclamar la extensividad del hecho estético a todos

\footnotetext{
16 "Veo estos objetos como el punto de partida para dejar de lado la situación estereotípica entre sillas de oficina, mesas y humanos" http://www.davidpompa.com/products/AU005-surreal-minimalism-collection-chair/ 03.06.2015

17 GIL, E. "Mentalidad de diseñador", en De lo bello de las cosas, Gustavo Gili, Barcelona 2007, p. 78.
} 
los ámbitos del entorno humano, en una disolución arte-vida"18. No hay, pues, una finalidad ergonómica en estos diseños, sino algo más allá, pues prima lo artístico, a pesar de 'camuflarse' en objetos cotidianos.

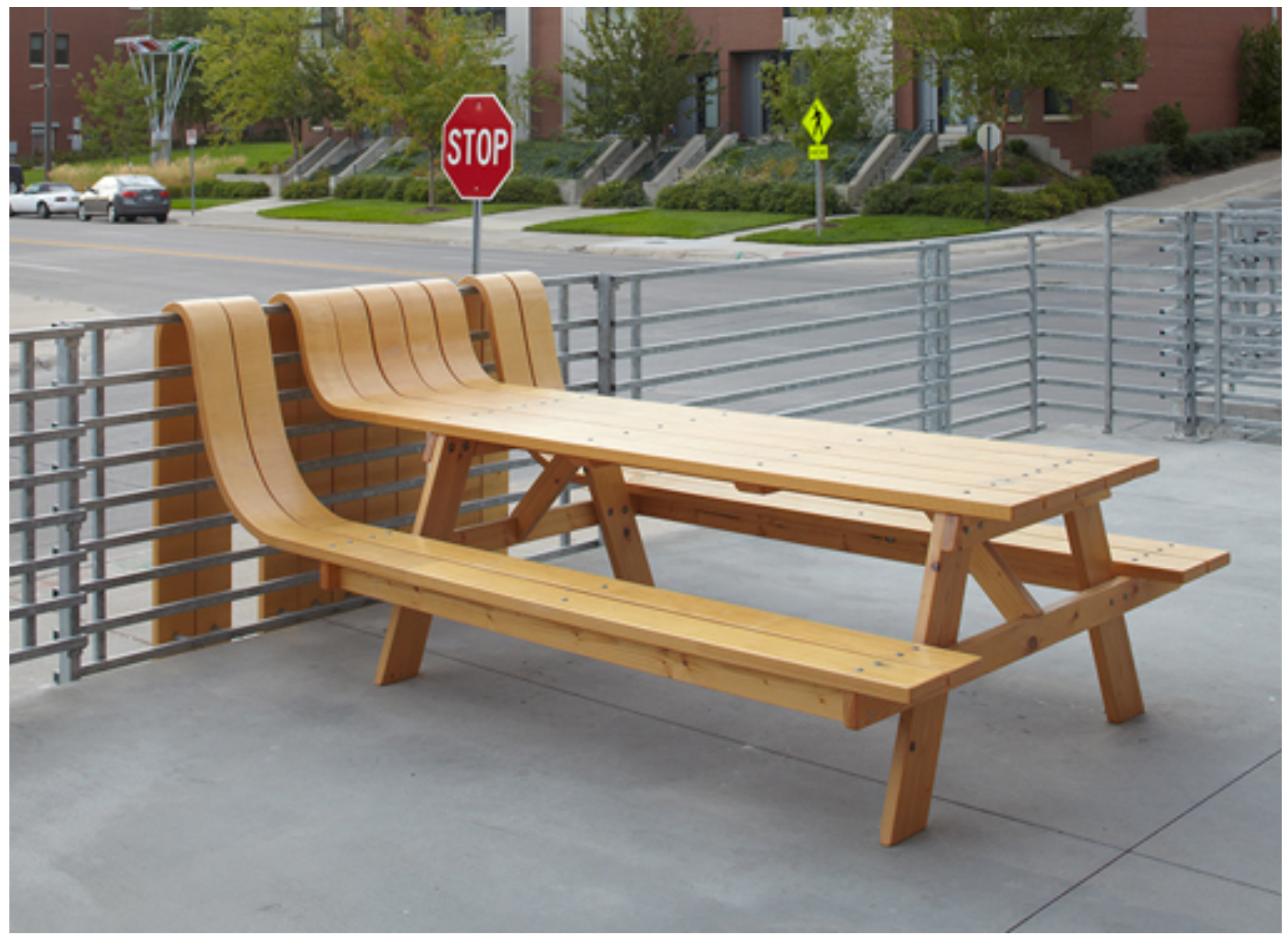

Fig. 8. It's not picnic table, Michael Beitz.

\section{Arte y diseño: un debate abierto}

Si bien el arte, en muchos casos, tiene una función estética (desvinculada de lo funcional), el diseño, por el contrario, guarda una utilidad y funcionalidad (a pesar de cuidar su estética). Sin embargo, a raíz de la posmodernidad y algunos de los ejemplos aquí expuestos podemos observar que algunos de ellos se sirven de cierta artisticidad y estética que a veces pueden suplir su funcionalidad, haciendo que nos encontremos con esta problemática.

Aunque resulta complejo ver hasta qué punto arte y diseño se ven influenciados, no podemos obviar muchas de estas similitudes, pues si hay algo que claramente las une es el hecho de que ambas "proceden de esa unívoca y única vena creativa con la que la naturaleza ha dotado al hombre" 19 .

\footnotetext{
18 RODRÍGUEZ ORTEGA, N. Manual de teoría y estética del diseño industrial. Universidad de Málaga, Servicio de Publicaciones e Intercambio Científico, 2001, p. 194.

${ }^{19}$ RICARD, A. “Diseño: ¿el arte de hoy?”, en Arte ¿? Diseño, op. cit., p. 97.
} 
Ante este debate entre arte y diseño la respuesta no siempre es del todo clara, incluso, entre los propios críticos e historiadores, ya que el arte dirige ahora su mirada hacia otras manifestaciones que se encontraban fuera del círculo artístico y cuyo cambio ya podemos observar desde los readymades hasta el arte conceptual más reciente. Por tanto, no debemos olvidar que son dos cosas diferentes, a pesar de que en ocasiones encontremos relaciones entre ambas. Es decir, estas fronteras no nos deben limitar sino enriquecer ambos campos.

Finalmente, ante ese despertar de los objetos, al que hacíamos alusión antes, cabe preguntarse ahora: ¿Se seguirán realizando esos objetos 'despiertos'? o, por el contrario ¿habrá una vuelta a la realización de otros más tradicionales, y, por tanto, 'dormidos'? La respuesta parece inclinarse hacia la primera opción, pues parece que la imaginación se ha despertado y manifestado de todas las maneras posibles, pasando del arte al ámbito del diseño. El arte contemporáneo no entiende de reglas y parte del diseño parece seguir estos pasos.
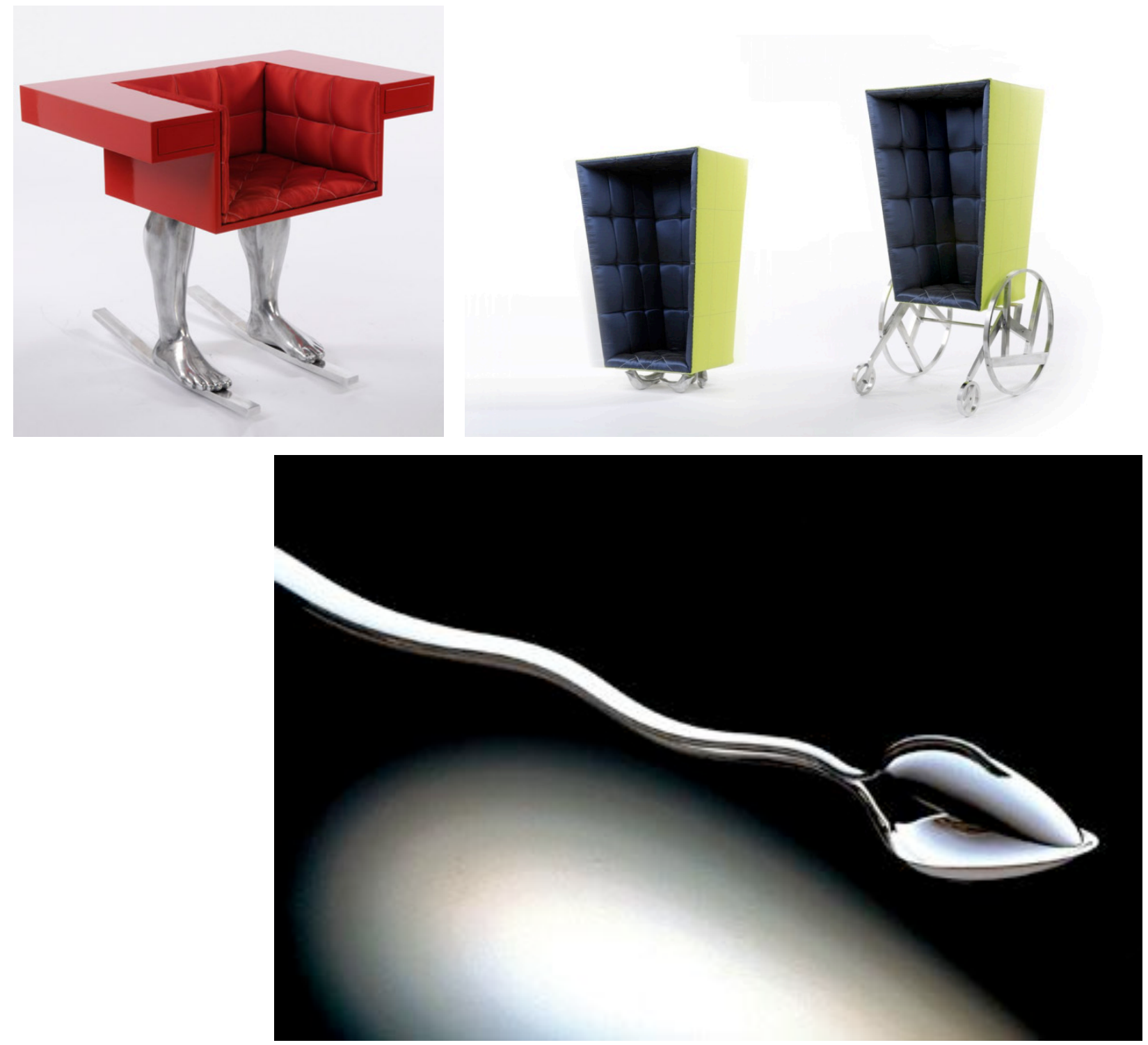

Figs. 9 y 10. (Arriba) Objetos realizados por David Pompa de la colección Surrealismo- minimalismo. Fig. 11. (Abajo) Cuchara de amor, Nedda El-Asmar para Robbe \& Berking, para la Fundación Carlos de Amberes, 2011. 


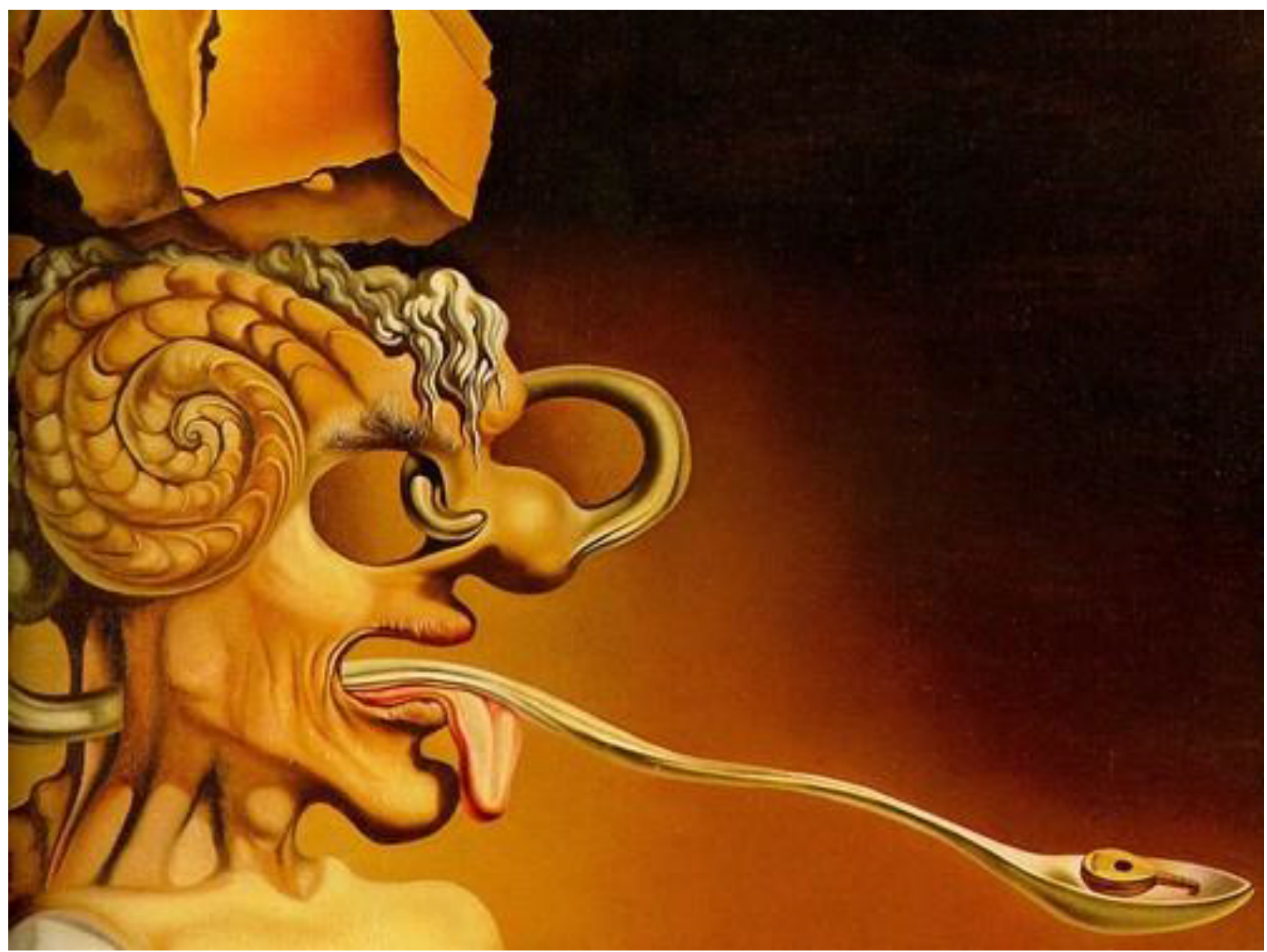

Fig. 12. Retrato de Picasso, Salvador Dalí, 1947, Fundación Gala-Salvador Dalí.

\section{REFERENCIAS}

ALBERA, G./MONTI, N., El diseño italiano, Gustavo Gili, Barcelona 1989.

BARREIRO LEÓN, B. "La estética surrealista”, Eikasia Revista de Filosofía, núm. 58, 2014, pp. 445-461.

BONET, J.M. El surrealismo y sus imágenes. Fundación Cultural Mapfre Vida Editorial, Madrid 2002.

BONET, J.M. y otros, El surrealismo, Cátedra, Madrid 1983.

BÖRNSEN-HOLTMANN, N. Italian Design, Taschen, 1995.

CALVERA, A. y otros, Arte ¿? Diseño, Gustavo Gili, Barcelona 2003.

CHARLOTTE y FIELL, P. Diseño del siglo XX, Taschen, 2000.

CIRLOT, Juan-Eduardo, El mundo del objeto a la luz del surrealismo, Anthropos, Barcelona 1990.

DUPLESSIS, Y. El surrealismo, Oikos-tau, Barcelona 1972.

FITOUSSI, B. Memphis, H Kliczowski, Madrid 1998. 
GAILLEMIN, Jean-Louis, Dalí: el gran paranoico, Blume, Barcelona 2011.

IBARZ, V.NILLEGAS, M. "El método paranoico-crítico de Salvador Dali", Revista de Historia de la Psicología, vol. 28, núm. 2/3, 2007, pp. 107-112.

JULIER, G. La cultura del diseño, Gustavo Gili, Barcelona 2010.

LÖBACH, B., Diseño industrial: [bases para la configuración de los productos industriales], Gustavo Gili, Barcelona 1981.

MARCHÁN FIZ, Del arte objetual al arte del concepto. Epílogo sobre la sensibilidad posmoderna, Akal, Madrid 1994.

PANERO GÓMEZ, A. “Dalí’s Gradiva”, Revista de Investigación Arte y Ciudad, núm. 1, 2012.

PUELLES ROMERO, Luis, El desorden necesario: filosofía del objeto surrealista, Universidad de Málaga-Servicio de publicaciones, 2002.

RODRíGuEZ ORTEGA, N., Manual de teoría y estética del diseño industrial. Universidad de Málaga, Servicio de Publicaciones e Intercambio Científico, 2001.

WOOD G. Cosas del surrealismo: surrealismo y diseño, Museo Guggenheim Bilbao, Ghislaine Wood, 2007.

\section{FUENTES DE LAS IMÁGENES}

Figura 1: La autora.

Figura 2: La autora.

Figura 3: Google images (dominio público).

Figura 4: Google images (dominio público).

Figura 5: La autora.

Figura 6: Google images (dominio público).

Figura 7: Google images (dominio público).

Figura 8: Google images (dominio público).

Figura 9: Google images (dominio público).

Figura 10: Google images (dominio público).

Figura 11: Google images (dominio público).

Figura 12: Google images (dominio público). 